ISBN 978-81-943403-5-5

18th ROME - ITALY International Conference on Art History, Literature, Social Sciences and

Education (AHLSE-20)

Rome (Italy) Feb. 3-5, 2020

\title{
Effects of Teaching Method on the Self-efficacy in a University Programming Class
}

\author{
KyungSook Lee ${ }^{1}$ \\ ${ }^{1}$ Professor, Korea University, South Korea
}

\begin{abstract}
This research proposes a teaching strategy adaptable to large class size environments to enhance the students' engagement and learning activity. Presenting questions or problems was one of the effective teaching methods that increase their involvement, even in a large class size. A sequence of well-defined activities come together to form a complete class[1]. The order of questions in the instructional activity could affect the outcomes of programming education. The aims of this experimental study were to determine the effects of presenting instruction activity in a different order and the interactions between teaching methods and gender in a programming lecture environment. The outcomes of this experiment is an identification of the joint effects of teaching methods and gender on the success of teaching programming, self-efficacy by non-majors. This result would also be useful in developing the new teaching model of programming classes
\end{abstract}

Keywords: teaching method, self-efficacy, class size

\section{Introduction}

Programming instructions given to college-level novice students have become increasingly widespread. Many studies have revealed that novice programming courses mainly instruct the syntax and semantics of individual language constructs [15]. At the beginning of learning programing, students memorize the basic syntactic and logic of a specific program language. Memorizing the syntax and logic, and repeated practice for learning programming basics could be very tedious, making it difficult to attract motivation. The drop-out rate of programming courses is relatively high [12]. The overall effectiveness of learners is poor [11].

On the other hand, many researchers have suggested possible solutions to try and overcome the difficulties that novice learner suffer. The offered solution was to focus on finding more effective teaching strategies with a cognitive apprenticeship approach within the lecture environments.

A onetime section in class was a series of a short lectures punctuated by a specific active learning technique designed to reach a wide range of learning styles [2]. This paper examines the effects on students' academic selfefficacy while learning programming by inserting the question activity before and after the modeling activity.

\section{Research Question}

1. To what extent is academic self-efficacy affected by types of teaching methods (question first, explanation first) and gender (male, female) in computer programming?

1) To what extent do types of teaching methods affect academic self-efficacy?

2) To what extent does gender affect academic self-efficacy?

3) To what extent does interaction between teaching methods and gender affect academic self-efficacy? 


\section{Literature Review}

Many teachers use scaffolding in various ways in instruction. Scaffolding is described as adult assistance that allowed a child or novice to solve a problem normally beyond his or her stand-alone capabilities. Scaffolding is a temporary support, which could be removed when no longer needed, but also could be reintroduced when necessary [8]. In the view of this classification, the cognitive apprenticeship and extreme apprenticeship both focus on using supportive scaffolding in teaching process. One of the objective learning programming is to improve cognitive thinking process and self-efficacy, so this study develops the model of teaching strategy with adding other forms of scaffolding such as question. The Extreme Apprenticeship model (XA) is based on a set of values and practices that emphasize learning by doing together with continuous feedback as the most efficient means of learning [10][15][16][7]. XA begins with exercises that are simple and achievable by students. Exercises designed to promote thinking are addressed at the appropriate level to the students [2]. The students are expected to spend most of the time in activity to solve programming exercises. Deek and Kimmel [6] designed the alternative method model, in which the first activity of the lecture session begins with a question. Questions can be used to generate discussions or as prompts for active learning exercises. Bonwell [2] also proposed the enhanced lecture model, in which the class starts with a quiz and discussion activities before presenting the lecture.

This study proves that students using the alternative methodologies received a higher grade than the class of students using the traditional approach. Academic self-efficacy refers to the subjective belief that one has the capability to execute the behavior to achieve a desired outcome [1]. In programming, academic self-efficacy shows a wide range of differences according to the individual. In programming learning situations, self-efficacy is also influenced by the amount of computer practice and activities, such as constructing the computer programming type of cognitive strategies adopted to solve problems [18].

\section{Method}

\subsection{Academic Performance Self-Efficacy}

In order to measure academic self-efficacy, developed by Bak \& Chai and redeveloped by Kim [9] was used. Academic performance self-efficacy is a Likert-type instrument which consists of twenty four statements divided into three subscales corresponding to three affective dimensions: information processing, self-study, and class attendance self-efficacy. The students were asked to rate how confident they were in performing each of the twenty hour tasks on six-point scale ranging from "complete confidence" to "no confidence at all". Construct validity was supported by confirmatory factor analysis, and criterion validity was supported by the correlation data with achievement. Cross-validation index and multi-group analysis suggested that the exploratory group's factor structure could be generalized to the validation group.

\subsection{Teaching Method}

The only obvious difference between the ways in which programming teaching is organized at the two groups is where the question is placed during class activities.

\subsection{Question first (group A)}

This study changed the manner in which programming is taught, focusing more on the question as a means of motivating language constructs. This study developed a question first approach to introductory courses in computer science. This approach followed a cognitive apprenticeship model of learning, where the class begins by the teachers' demonstration and explanation of programs written by an expert, students' practice of coding the program with scaffolding, and coaching by teacher.

\subsection{Explanation first (group B)}

This teaching method is more close to traditional teaching method focusing on explanation with workedexample. 


\subsection{Data analysis}

The design of this study is a 2 by 2 factorial design. The two factors are the teaching method and gender. The first independent variable, the teaching method, had two levels, the question first method and the Explanation first. The other also had two levels, female and male. .

MANOVA was conducted to analyze Interest and Creativity. The MANCOVA and MANOVA were tested using Pillais'trace criterion. In addition, Follow-up ANOVA was conducted to analyze self-efficacy. The Statistical Procedures for Social Sciences (SPSS) was used to code and analyze the data.

\section{Results}

This study aimed to investigate the effect of teaching methods for computer programming constructing. The study investigated the programming language learners' constructing performance after being taught by question first teaching method, and compared their performance scores to the scores produces by the comparison group which were taught by explanation first teaching method in writing programming. This chapter reports the results from the quantitative analysis of data, in which examined whether there was an impact of a question first teaching strategy on participants' constructing computer programming.

\section{Results for Research Question}

A two-way ANOVA showed significant main effect of teaching method, but non-significant main effect of gender on academic self-efficacy. This result shows that a teaching method affects academic self-efficacy. Question first teaching method resulted in higher scores on academic self-efficacy.

Table I : ANOVA Descriptive Statistics

\begin{tabular}{lllll}
\hline method & gender & Mean & Std. Deviation & $\mathrm{N}$ \\
\hline QFirst & Female & 103.50 & 10.698 & 12 \\
& Male & 103.58 & 11.196 & 12 \\
& Total & 103.54 & 10.710 & 24 \\
\hline EFirst & Female & 98.75 & 17.899 & 12 \\
& Male & 92.83 & 12.634 & 12 \\
& Total & 95.79 & 15.450 & 24 \\
\hline Total & Female & 101.13 & 14.624 & 24 \\
& Male & 98.21 & 12.901 & 24 \\
& Total & 99.67 & 13.721 & 48 \\
\hline
\end{tabular}

Table II : ANOVA Data Analysis

\begin{tabular}{lrrrrr}
\hline \multicolumn{1}{c}{ Source } & df & $\begin{array}{c}\text { Mean } \\
\text { Square }\end{array}$ & F & Sig. & Partial Eta Squared \\
\hline TMethod & 1 & 720.750 & 4.005 & .052 & .083 \\
\hline gender & 1 & 102.083 & .567 & .455 & .013 \\
\hline TMethod * gender & 1 & 108.000 & .600 & .443 & .013 \\
\hline
\end{tabular}




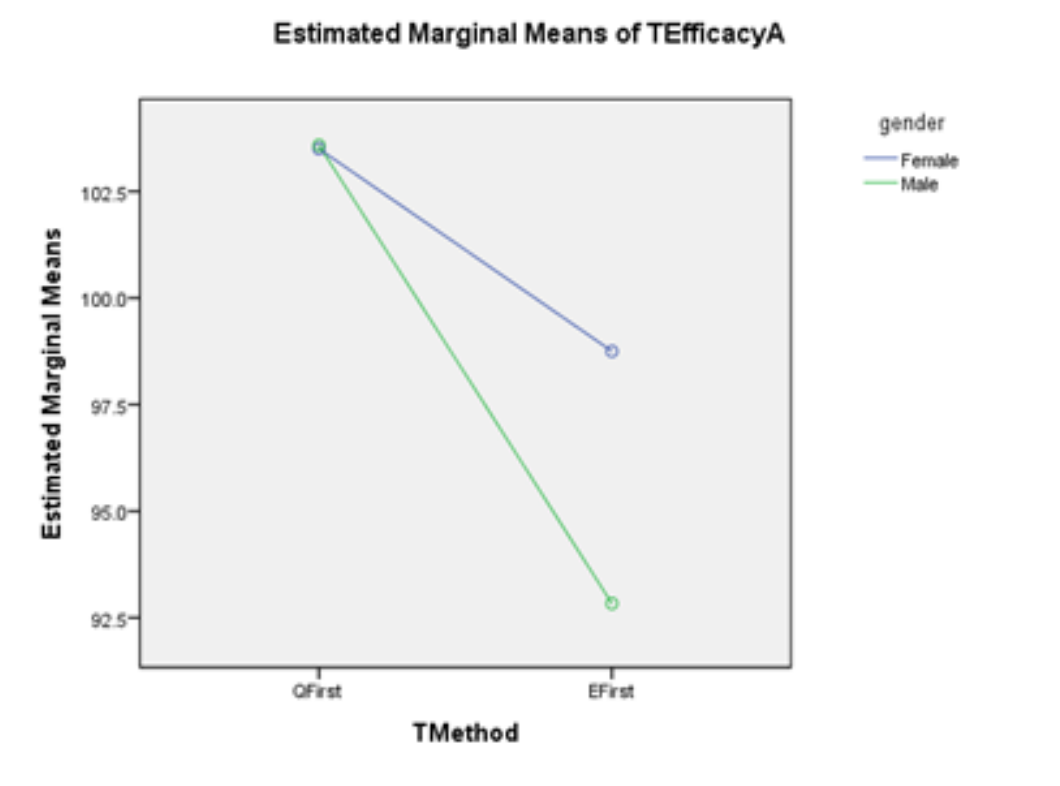

\section{Discussion \& Conclusion}

\section{Summary of Findings}

The results of this research can be summarized in terms of a few key findings. This study aimed to examine the effects of the interactions between the teaching method and gender. In the following paragraphs, the subsequent topics are addressed.

Shashaani [14] also showed that females' grades were not affected by their lower level of interest. The teaching method did not affect the academic self-efficacy significantly, however can be noted to have been close with $\mathrm{p}$-value $=.052$. The question-first group acquired higher scores than the explanation-first group for both females and males.

\section{Discussion}

Research concentrating on the diverse outcomes according to different learning environments estimated that, for girls, positive attitudes and comfort levels toward learning are developed in cooperative group learning situation (Clarke \& Chambers, 1989). Davies [5] concluded that girls showed more consistent work styles and often try to find a solution to potential difficulties before they become real problems, whilst boys showed more tendency to deny the fact that there is a problem until it can no longer be solved. This result provided an explanation of an important factor to address the issue of why more female students seek help to solve problems. This analysis also provided the information that there are differences in the ways in which male and female students approach learning.

Using creative methods for teaching Microsoft result in increasing students' motivation [3]. Romeike [13] presented requirements for the creative teaching environments. First, being creative means to experiment with ideas, to explore the possibilities to solve a problem. Second, time is necessary to estimate and recognize ideas. Third, new ideas need to be accepted and various solutions supported. Fourth, the teacher assists only where a problem cannot be solved by a student himself instead of being in the leading role of transferring knowledge. Comparing with two teaching methods, the question-first pedagogy provides more chance to experiment, considering time and opportunity, to try to construct diverse solutions rather than in the explanation-first pedagogy

Learners estimate their ability to perform based on hands-on experience with task. If the tasks are not too difficult then students who, in the early part of the course, were able to build deep knowledge had strong confidence in their capability to solve a wide range of programming problems under a variety of conditions [17]. 
If adequate questions were given comparable to the learners' abilities, then the learners succeeded to construct and execute programming, which in turn raised academic self-efficacy more than by having an easier learning process. The result of this study fits well with the self-efficacy theory.

\section{Concliusion}

Adequate level of questions was given comparable to the learners' abilities, then the learners succeeded to construct and execute programming, which in turn raised academic self-efficacy more than by having an easier learning process. With regard to the idea of providing adaptive teaching support, the interaction between other factors such as self-efficacy, interest, and teaching methods is studied much more to be applied in a real programming class. This research provided the information that there are differences in the ways in which male and female students approach learning and the interaction between these differences and teaching method result in discrepancy of outcomes

\section{References}

[1] Bandura, A. (1997). Self-efficacy: The exercise of control.

[2] Bonwell, C. C. (1996). Enhancing the lecture: Revitalizing a traditional format.New directions for teaching and learning, 1996(67), 31-44.

https://doi.org/10.1002/t1.37219966706

[3] Chaytor, L., \& Leung, S. (2003, October). How to creatively communicate Microsoft. NET technologies in the IT curriculum. In Proceedings of the 4th conference on Information technology curriculum (pp. 168-173). ACM.

https://doi.org/10.1145/947121.947160

[4] Clarke, V. A., \& Chambers, S. M. (1989). Gender-based factors in computing enrollments and achievement: Evidence from a study of tertiary students.Journal of Educational Computing Research, 5(4), 409-429.

https://doi.org/10.2190/L4FC-Y6EV-VLUA-7N29

[5] Davies, L. (1983). 3. Gender, Resistance and Power. Gender, class \& education, 39.

[6] Deek, F. P., Kimmel, H., \& McHugh, J. A. (1998). Pedagogical changes in the delivery of the first-course in computer science: Problem solving, then programming. Journal of Engineering Education, 87(3), 313

https://doi.org/10.1002/j.2168-9830.1998.tb00359.x

[7] Hautala, T., Romu, T., Rämö, J., \& Vikberg, T. (2012, July). Extreme apprenticeship method in teaching universitylevel mathematics. InProceedings of the 12th International Congress on Mathematical Education (pp. 8-15).

[8] Jackson, S. L., Krajcik, J., \& Soloway, E. (1998, January). The design of guided learner-adaptable scaffolding in interactive learning environments. InProceedings of the SIGCHI conference on Human factors in computing systems (pp. 187-194). ACM Press/Addison-Wesley Publishing Co.

https://doi.org/10.1145/274644.274672

[9] Kim, S. S. (2010). Effects of Scatch Porgramming Insruction Based on Game Making on Self Efficient Academic Performance.

[10] Kurhila, J., \& Vihavainen, A. (2011, October). Management, structures and tools to scale up personal advising in large programming courses. InProceedings of the 2011 conference on Information technology education (pp. 3-8). ACM.

https://doi.org/10.1145/2047594.2047596

[11] Renumol, V., Jayaprakash, S., \& Janakiram, D. (2009). Classification of cognitive difficulties of students to learn computer programming. Indian Institute of Technology, India.

[12] Robins, A., Rountree, J., \& Rountree, N. (2003). Learning and teaching programming: A review and discussion. Computer science education, 13(2), 137-172.

https://doi.org/10.1076/csed.13.2.137.14200

https://doi.org/10.17758/HEAIG7.H0220426 
[13] Romeike, R. (2008, November). Towards students' motivation and interest: teaching tips for applying creativity. In Proceedings of the 8th International Conference on Computing Education Research (pp. 113-114). ACM. https://doi.org/10.1145/1595356.1595380

[14] Shashaani, L. (1997). Gender differences in computer attitudes and use among college students. Journal of Educational Computing Research, 16(1), 37-51. https://doi.org/10.2190/Y8U7-AMMA-WQUT-R512

[15] Vihavainen, A., Paksula, M., \& Luukkainen, M. (2011, March). Extreme apprenticeship method in teaching programming for beginners. In Proceedings of the 42nd ACM technical symposium on Computer science education (pp. 93-98). ACM.

https://doi.org/10.1145/1953163.1953196

[16] Vihavainen, A., Paksula, M., Luukkainen, M., \& Kurhila, J. (2011, June). Extreme apprenticeship method: key practices and upward scalability. InProceedings of the 16th annual joint conference on Innovation and technology in computer science education (pp. 273-277). ACM.

https://doi.org/10.1145/1999747.1999824

[17] Wiedenbeck, S. (2005, October). Factors affecting the success of non-majors in learning to program. In Proceedings of the first international workshop on Computing education research (pp. 13-24). ACM.

https://doi.org/10.1145/1089786.1089788

[18] Karsten, R., \& Roth, R. M. (1998). Computer self-efficacy: A practical indicator of student computer competency in introductory IS courses. Informing Science, 1(3), 61-68.

https://doi.org/10.28945/615 